\title{
FOOD OR FAMINE FOR THE FIFTH BILLION INTERNATIONAL BIOLOGICAL PROGRAMME
}

\author{
by Dr. T. W. M. Cameron, McGill University, Montreal
}

EDITOR:S NOTE: Dr. Cameron, Emeritus Professor in the department of microbiology and immunology in McGill University, is chairman of the Canadian committee on the International Biological Programme. The following paper on this very important topic was given in Regina as the University of Saskatchewan's sixth Basterfield lecture on October 5,1967 . We are pleased to be able to share it in its entirety with Blue Jay readers.

Perhaps the most important consequence of the establishment of Evolution as a doctrine, was the acceptance of man as a member of the animal kingdom - a rather recent and somewhat primitive mammal both physiologically and physically with, however, a considerable development of its brain. This gave man a mental advantage because of the extent of his intelligence and his ability to communicate with his fellows. Nevertheless, he has remained biological rather than logical in his actions and he is guided much more by instinct than by reason. Thinking to most men is at best an intermittent process and is employed only under stress. $\mathrm{He}$ is much less rational than he believes himself to be, and the two ruling motives in his behaviour are pain and pleasure. To the great majority of mankind, material and non-intellectual pursuits have always predominated and probably always will.

In his origins, man was an unisocial creature who lived in small family groups until the need for assistance in hunting and in protection against his innate helplessness, forced him to form larger units. He is still not really a social animal and he is still very much at the mercy of the conflicting effects of instinct and of reason - and instinct almost always predominates.

The tribal units have enlarged and the populations they constitute can be studied in the same way as the populations of other animals. All, whether man or beast or bird, follow an almost identical pattern.

In any given environment in which suitable foodstuffs exist, the population increases in numbers. The rise is slow at first but it becomes faster and faster until, as the result of a variety of causes - predators, disease, food shortage - it gradually levels off at a density which represents a state of equilibrium. This development plotted as a graph against time, shows an S-shaped curve in which there are of course, numerou's small irregularities. The upper arm of the $\mathrm{S}$ tends to continue for long periods at the same general level, unless some catastrophic event disturbs it. In this case, if the population has not been exterminated, the sigmoid curve starts again, quite often with the population somewhat changed in character.

This kind of expansion was at the base of thought expressed nearly two hundred years ago by Brückner and Malthus; they were considering the same problem - although on a much smaller scale - as the one we are discussing today. 1500 years ago the human population of the world was increasing at the rate of $2 \%$ each century. A few years ago it had increased at the rate of $2 \%$ a year and now it is $3 \%$ yearly.

Man began his evolution as a nomad hunter and a collector of wild grasses. When he found how to tame some animals and grow some grasses, he became an agriculturist. The first settlements and the first tribes were thus created; numbers began to increase and the curve of human populations began to move upwards. As man's efforts at animal husbandry and agriculture improved, some individuals were released from the soil and became urbanised. These still had to be fed and clothed of course, and as numbers of the non-agriculturists increased, demands on the soil correspondingly increased, so that as a result, it gradually lost its original fertility. 
The settlements had to put part of their wealth back into the soil to restore and increase its production. The population curve continued to soar geometrically and Man had commenced his interference with Natural Selection. Science came to the aid of his earlier efforts and showed him how to increase food production to an abnormal extent. This enabled more and more people to live on the fruits of fewer and fewer, and urbanisation increased. The town worker became industrialized and produced material goods which increased the physical well-being of the population, and later-often after catas.trophic epidemics of disease - he was able to devote some of this wealth to the prosecution of health. There is, however, a limit to the amount of usable wealth which can be created; production becomes restricted and fails to support the increasing expense of fertilizing the land which again loses its fertility. Numbers are approaching the point where the curve starts to flatten out.

The world still consists of many individual populations, all of them at different levels of development. The primitive lands of Africa with their poor soils and increasing peoples are still in the first stage. Those of the temperate world are on the upward slope of the curve; western Europe is probably highest, with North America not far behind and quite closely followed by the U.S.S.R. The old civilizations of the subtropical belt-south Europe, north Africa, and southeast Asia - are approaching the phase when the land is again losing its fertility and the curve is beginning to flatten out. The hungry states are those at the bottom and top of the sigmoid curve.

Everywhere in the world, however, people are still increasing in numbers, and this again, is due to man's attempted revokement of the Law of Nature which requires the Survival of the Fittest. This law operates through disease and parasites, through hunger, through selective breeding, and keeps the population at the level con- sistent with normal health and well being. Man has affected and is stil altering this with his domestic plants, with his domestic animals and above all, with himself - mostly himself The consequence of breaking this law has always been the extinction of the species. Only man has dared to defy it but not even man has been able to repeal it.

Nature deals with the species and is careless of the individual; man, who is less wise than the Nature he has partially supplanted, deals with the individual and is carelesis of the species.

It is difficult to realize the enormous revolution in public health which took place during the first half of this century. Although no infectious disease has as yet been eradicated, many have become exceedingly rare and most others are in the process of control. In the temperate parts of the world, diptheria, typhoid, lousecarried typhus and relapsing fever are almost unknown. Yet during the first World War, the louse-carried diseases alone killed several million people.

Smallpox also has almost gone and so has plague, while tuberculosis has been steadily declining and but for wars, would probably be as rare as the others.

The greatest advances, however, were in the tropical lands. Malaria sleeping sickness, yellow fever, cholera, schistosomiasis and hookworm disease began to be subject to control. Many of these are epidemic killing diseases but many also are endemic debilitating diseases which lower life expectancy, enfeeble the patient, reduce his working potential and render him subject to numerous non-specific conditions. The effects on infant mortality have been striking, although faulty feeding still takes its very considerable toll.

It is perhaps important to note that the improvement of life expectancy in the tropics was mainly if not entirely, due to colonial administration which not only prevented tribal warfare but undertook the control and 


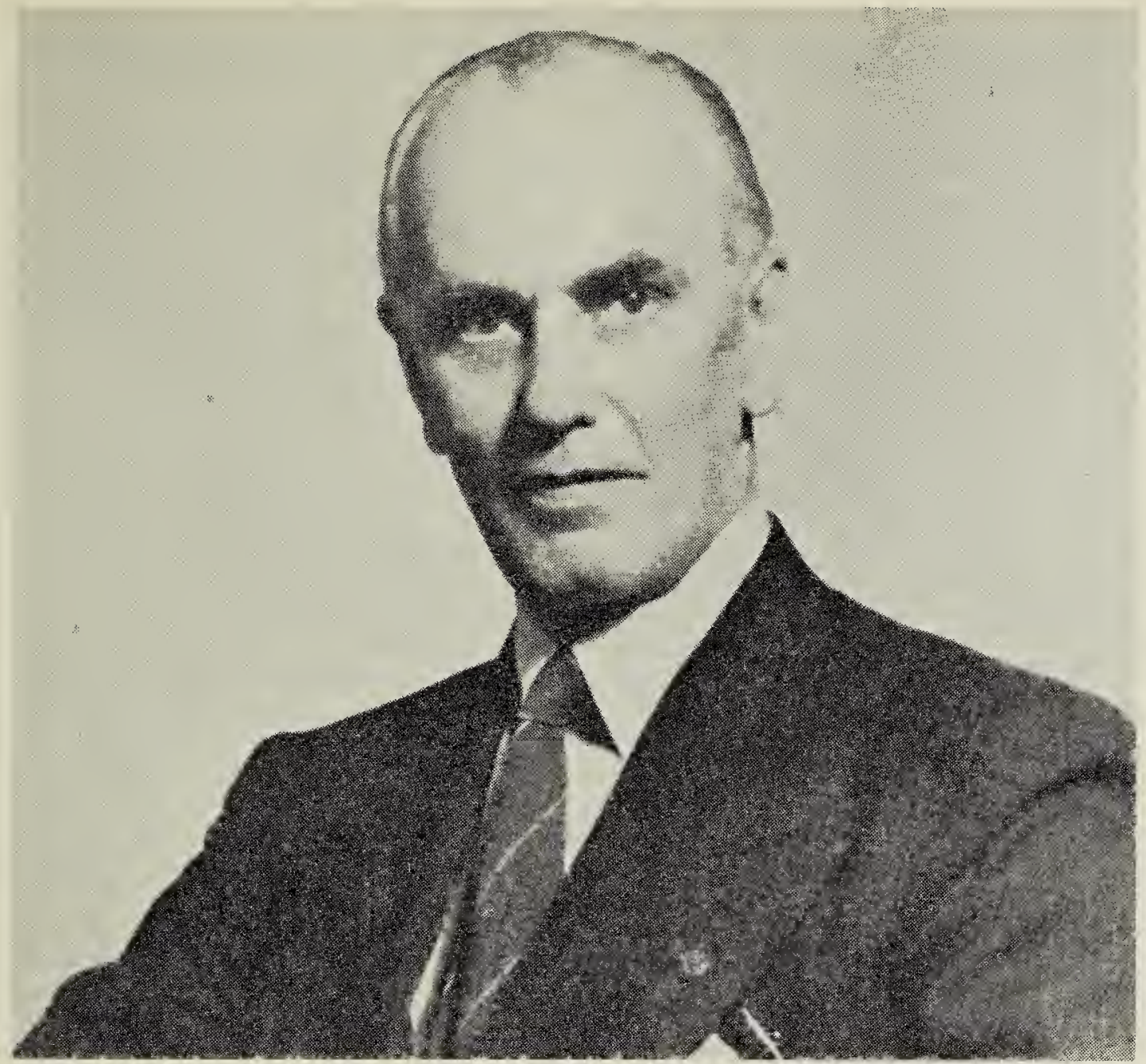

Dr. T. W. M. Cameron

prevention of both the debilitating and killing diseases. Colonialism more than all other factors, is responsible for the population pressures in the so-called underdeveloped lands.

Although in the more advanced communities with their higher standard of living, social resposibility and family planning, there is a tendency to limit the birthrate, in reasonably unsophisticated primitive communities, the crude birthrate is about fifty per thousand. Because of the relative absence of serious disease and the continual excess of children who survive, the crude death rate is about eight to ten per thousand. It follows that, if this rate continues those communities will double themselves every twenty to thirty years.

By the end of this century the population of the world will have increased from its present 3,400 millions to about 5,000 millions. It is a sobering thought to realize that the human beings at present alive, represent about three per cent of all who have ever lived and that almost half of the present population has been born since World War II.

Prevention of disease is still far from complete, however spectacular the results have been so far. Nevertheless, in the less sophisticated countries preventive medicine has outstripped improved nutrition, and the increased population, which will continue to increase, is becoming more and more hungry.

The second factor controlling natural populations is food. The effect of better nutrition is considerable - not only is there better resistance to disease, a longer life and better ability to work, but more babies are born and infant mortality is reduced. Adequate nutrition therefore, means a further increase in population. Nevertheless, the already dull and monotonous diet of about two-thirds of mankind is now verging on malnutrition or actual starvation.

Now, a single Canadian wheatfarmer can produce enough wheat in 
a year to provide a subsistence diet for 800 persons. He uses wide tracts of good land and elaborate machinery. One able bodied man in the tropies on the other hand, with simple tools, can produce only enough for six persons. If he can use draught animals he can produce, say fifty per cent more while, if, with better fertilizers and better tools, he can double his output, he can feed six to twelve persons and release them for occupations other than foodgetting.

It is estimated that about $40 \%$ of the land surface of the world is of little use to mankind, that $10 \%$ is used as arable land, $20 \%$ for hay and pasture and $30 \%$ as forest.

It is believed that if all the land known to be suitable for farming, was cultivated with presently known techniques and skills, the world could produce food for ten or more times the present population. There is, of course, little hope of this happening although we may expect food production by the end of the century to be not only of better quality but to be about three times as great as at present.

The most important duty of any impoverished country is to feed its nationals adequately, preferably on home-grown food-crops rather than on food bought from already overwealthy countries as the result of exported "cash" crops. Agriculture is its most fundamental problem.

The first requirement of agriculture is water. Much land once fertile, is at present useless and so a first step must be land planning. There are vast tracts of land, including much of the Sahara Desert, which once were fertile lands. Some of these tracts could be reclaimed for re-use, particularly if fresh water were available.

After water, comes the need for the chemicals necessary for plant growth. These may be inorganic salts or complex organic mixtures. Modern scientific methods of refertilizing poor lands can be instituted. One of the great problems affecting the whole world is the disposal of organic waste, much of which, properly processed, could and should be used as fertilizer.

After reconditioning, the land must be used wisely in terms of what a diet should contain. Thus, in the tropics good sugar-cane land will produce about 100 tons of sugar per acre while good wheat or rice land will produce less than half this amount of wheat or rice. But sugar is pure carbohydrate, whereas the cereals have a high protein content - and protein is essential for growth, development and survival.

It is accepted that an adequate diet should contain about 15 per cent of protein. It musit be remembered that the common starchy foods contain some ten per cent. Part of the remaining five per cent, could be obtained from a variety of other sources - such, for example, as new varieties of green plants suitable for tropical cultivation. Actually, in many undernourished countries the required amount - some twenty million tons - is produced annually even now, as a by-product from the extraction of oil from the high protein seeds grown there; the oil is exported, however, and most of the residue is used to feed animals or make fertilizer or is even wasted.

The best kind of usable protein is of animal origin and it is generally agreed that there should be some animal protein in the diet. In an impoverished country, the conversion of vegetable protein into animal protein by feeding cattle, sheep and pigs in the conventional manner, is not an economical procedure. There is, however, no reason at all why attempt should not be made to exploit lands unsuitable for human food crops by domesticating new species of ruminants. There are several in Africa already almost domesticated-such as the eland, which can become fat on desert lands on which cattle would starve. As a ruminant is a bacterial factory in which micro-organisms convert into protein and fats plants which to us would be unusable, it can utilize lands unsuitable for the 
production of food crops, or even synthetic materials unsuitable for human nutrition.

Other sources of food stuffs are also still very inadequately exploited, and it is of interest to note that of some 250 plants in cultivation, 180 have been in use for over 2000 years -some of them for over 4000 years. Only 70 plants have been introduced since 1 A.D.

The world consumption of fish, for example, is estimated to be about one-fiftieth part of man's diet; that is, about one gram of fish protein per head; this is less than $1 / 10,000$ th part of the annual produce of the sea. We have made no essential changes in our methods of fishing in the last 50 centuries. Fish production could be increased by bringing the fertilizing salts from the deeps to the surface to supply the raw material for photo-synthesis and the production of the plankton which ultimately forms the food of fish. This is what actually happens in the great Humbold Current off western South America where the deep currents from the Pacific rise against the precipitous continental shelf to mix their minerals with the surface waters, and so make them the richest fishing grounds in the world. It is well within the bounds of possibility to do this artificially, provided of course, that the disposers of radioactive wastes do not continue their present irresponsible action of dumping over ten million gallons of atomic waste into the sea each year, and so make fish lethal to eat.

Healthy animals and crops, free from disease, would greatly increase the value of even our existing agriculture.

Much of our attention in the past has been concerned with those diseases and parasites which affect man. More recently we have started to investigate the more acute epidemics affecting animals and still more recently, the diseases and pests of food plants. We are even now in a position to control and probably eradicate the acute infections in animals, but we have done virtually nothing about the chronic ones which year in and year out rob us of millions of tons of high grade protein. Pests and diseases in our plants cause an even larger and more important loss of foodstuffs, a loss which cannot be estimated accurately but may well be between onetenth and one-sixth of all the crops harvested - enough to feed about 200 million people.

Having planned how to improve the land and increase its yield, the next step is to work it, by inducing men to become farmers. In an industrial country in which most people live away from the land in towns and cities, this can be done by offering material inducements - money, machinery. The problem in a non-industrialized country or one which is in process of so developing, is quite a different one. Either the farmer serves a very small community or he is tied to the land to serve the larger communities which are in process of being urbanised. No matter what the course, a healthy agriculture is essential for any kind of industrial development.

Farming is not always regarded as a very desirable occupation but it is undoubtedly the fundamental trade of mankind. More efficient farming is the base on which any under-developed country must build its future. But unless and until the community is able to provide the farmers with the necessary inducement, compulsion from inside or help from outside in the form of foodistuffs and capital to enable the community to become a producer, are necessary.

No one has as yet given much thought to tropical urbanisation and it undoubtedly requires a great deal of thought. Nor has the question of how to industrialize the warm countries been considered. Certainly what we consider industrialization in the north is quite unsuitable. It is a moot question indeed if these tropical countries should be industrialized. Why, for example, should the tropical native wish to become a factory worker and, in spite of the climate be made to suffer a western civilization? What 
right have we in our ignorance, to attempt to mould him in our image? Why should he wish to undertake our kind of work--even for himself?

The whole tendency in our western civilization is to decrease the time spent at work and to increase leisure. In the tropios, the native can do this even now. In the temperate zone with its cold winter we must work - or put machines to work - to provide shelter, heat, and clothing. In the tropics none of these are essentials and food can be picked from the trees. Why should we make tropical man work in our manner against his own inclination?

The population increase is a world problem in that in some way or other, it affects all countries, socially, politically or economically. Each country thinks essentially in terms of its own nationals, no matter how high its moral outlook and, in consequence, each country has a different series of problems.

We, in North America, entered into a virtually empty continent which has been swept clean by the Pleistocene ice and rendered fertile by its action. We borrowed extensively-our plants and animals from the Old World and from South America, the ideas on which we built our modern culture from the older civilizations, and our populations from all the countries of the earth. It is obvious that a time for accounting for this debt is near at hand and we have to consider how to repay it.

The western world's populations also are increasing. We still have surpluses of food, although we are running short of water. We probably can secure water from the sea - in fact, we have already started to do soand we can secure power from the sea, the sun or the atom. We have eliminated most infectious diseases and soon will eliminate the others, but we are still far from eliminating or even understanding those non-infectious endogenous diseases which are becoming increasingly common. We cannot eliminate death or the degenerative diseases of old age, but we can probably lengthen the average life span still farther than at present. For a long time to come, accordingly, we shall have more and more people of a mature age, well fed, and free from nutritional worries.

Some of our resources are still adequate but we are running short of minerals. It might be well to stop and think what are resources. Quite obviously they must be living things or sources of power which can be renewed. In the true sense - and the distinction although not often made, is of fundamental importance-they do not include minerals or fossil fuels - they do not even include sources of atomic energy. These cannot be renewed and someday will be exhausted. True resources constitute income whereas minerals constitute capital.

We are rapidly depleting our own resources, often without attempting to replace them for the future. Worse still, we are wasting our own assets at an appallingly rapid rate, and we cannot replace them at all - at best we can only substitute.

It comes as a surprise to most of us to realize for example, that in the last fifty years, more minerals have been consumed than throughout the whole previous history of mankind. While this is true of both metallic and non-metallic minerals, the situation is particularly critical with respect to the metals which are even now approaching the point of exhaus. tion. If we continue our present wasteful use of copper, lead, tin and zinc for example, we may expect the available supply to be exhausted by the end of this century; iron will last until well on in the next century when it too will become scarce. These are optimistic figures which assume no great increase in consumption out side of our western culture; if the un. developed lands increase their indus. trial demands, the time of exhaustior will be even sooner, unless new sup. 
plies are found much deeper in the earth or taken from the sea. Conservation of metals is a matter of supreme importance to the world, and especially to North America which annually consumes over three times as great a quantity of these metals as the rest of the world combined many of the ores being obtained from the undeveloped countries.

Our present sources of powerother than wind and water - are the so-called fossil fuels - coal, petroleum, natural gas - and these also are rapidly being exhausted. We are using the reserves of these-large as they are-at an increasingly alarming rate - and we are consuming not only our own reserves but those of the backward peoples.

Our western culture, the organized behaviour of our society, has evolved in a biologically unnatural environment - one in which man can live in places and under circumstances which otherwise would be impossible. Consequently, during the evolution of this culture, our efforts have been focused on the improvement of our material environment and our technology has developed at a progressively increasing rate - probably faster than the multiplication of our populations. But it is also impairing our natural resources and has virtually destroyed our assets. Even more important is the need for planning ahead. Our technology has stampeded our civilization and, like a runaway horse, it must be restrained if that civilization is to survive.

In many parts of the world, the fear of hunger which has accompanied man throughout the ages, is still present. Less than a hundred years ago, a world shortage of food was predicted for 1930 . Actually by then, our food balance in North America was greatly in excess of our domestic needs and since then we have made great advances in soil chemistry, in plant nutrition, in animal physiology and disease and its control. New varieties of food plants have been found and new techrical methods of production, storage and distribution have been developed. Canada at present is in a very fortunate position but there are still millions of human beings who are inadequately fed and clothed; the situation is steadily deteriorating and in many lands actual starvation can be expected to replace the present malnutrition. By 1980 , an additional 1000 million people will be requiring food and 20 years later, the world population will be double what it is today.

Our problems and our responsibilities, however, are by no means confined to our own way of life. We are inevitably concerned with the problems of the underfed people of the world because we in large part have, directly or indirectly, produced these problems by our ethics, our commerce, our preventive medicine and our technology. It is the northern peoples who have attempted to replace Natural Selection by artificial selection but who have, without thought for the consequences, failed to provide an adequate system of control. We have made no attempt to improve on Nature's methods of balancing the population.

There is no panacea for the problems resulting from these increasing numbers. To assume that our method of life, our type of industrialization, our economy of waste, can be applied as it exists to the needy parts of the world is simply wishful thinking. However, there are many ways of exploiting existing knowledge which we have not yet attempted to apply to the existing situation.

The first step in our thinking of these problems requires the cultivation of a sense of geography and anthropology. The problems essentially are those affecting man in a specific environment of soil and climate and with habits resulting from centuries of living with disease and malnutrition.

The second step is an increased and intensive research in the fundamentals 
of agriculture and animal husbandry; basic research is more easily inaugurated at least, in a temperate climate. Infinitely more important than any of our much publicized scientific efforts, is the problem of producing more food - food of a type suitable for growing and use in the specific areas of the world where it is most needed. We have done comparatively little to use our tropical forests or our northern wastes for food production. Agriculture is applied photosynthesis, the ability of plants to utilize the energy of sunlight and probably the most important avenue of research today is to discover the secrets of this process.

The third step is the application of our existing knowledge to those parts of the world which stand in need, so as to enable them to develop their own resources and to use them for their own advantage rather than ours. This will involve training of these people at a level which will be understood by the primitive agriculturist. This means education and propaganda of the most basic and most important kind.

Charity is no answer to their problems. Free food is a palliative measure and so is renewed public health effort, unless steps are taken locally to make the people self-supporting. Immigration is no answer either; the population will continue to increase at a rate which will neutralize this help. There is no doubt whatever that for decades to come, we shall have too many people with too little food, most of them with too little help and knowledge to maintain health, and too little control of their own assets and resources.

The only answer is in increasing food production locally at a rate faster than the increase in population. This it is true, is only an interim step but it will help the present situation as well as that which will develop for some years to come. The production of more and better food however, cannot be achieved immediately, because the techniques must be employed by the countries themselves. Even present considerable knowledge of agricultural and soil sciences, of reasonable nutrition and better personal health can only be applied by the people themselves. This involves instructors who not only understand the local social customs and cultures, but who can explain simply and convincingly how to improve them. There is still only a very minor place for the high powered scientist in most of these countries and the vital need is for very simple training rather than post-graduate university education. Culture, the result of education, has as its function the making of a life, training, that of making a living, and in these underdeveloped countries, training must come first. Low living and high thinking is a product of old established cultures.

We have confined this discussion so far to the immediate future. The solution of these problems is presently possible, provided we are prepared to undertake the necessary revision of our own way of life and to plan on a world basis. In the past decade we have seen an average increase of nearly $20 \%$ in the crops of the world. The greater problem still remainshow to balance births and deaths, not only at home but throughout the world and hold them on a level which will correspond to the upper portion of the population curve.

So far, we have no satisfactory answer to this problem. If it is not to result from an increase in the proportion of deaths from starvation, disease or war it must come by decreasing number of births. There are no possible alternatives; unless this is done, sooner or later the world will reach a stage when there are far too many people - a situation which means universal catastrophe.

We are in the third of a series of major population increases. The first followed the discovery of agriculture, the second the advent of industry, the present, the conquest of disease. The first was universal; the second was 
essentially a feature of western civilization which only now is affecting the rest of the temperate zones. The third, built on the other two, is really only beginning but it is universal in its scope. A variety of factors have prevented the first two rises from becoming catastrophic - the most important of these being disease and violent death -nature's most usual cure for too large and unmanageable populations. We can still further reduce disease even if we cannot eliminate it; we can possibly reduce violent death (even though we are killing more people in North America by automobiles than we ever have done by war) and so, in the future the controlling factor in the population of the world must be the extent of our resources-those materials and sources of power which we can renew. These resources are finite and the wise utilization of these for the whole world will determine the actual maximum level of the total population. We have not yet reached this stage and we shall not for some generations to come, but the time to start constructive thinking about ways and means is now. There is no evidence that human intelligence is increasing, either in quantity or quality, and consequently the thinking process will be slow and lengthy. Accordingly, all the potential intelligence of mankind must be exploited thoroughly and promptly. The present is almost past and we have to begin to face the future.

In spite of all the advances of the past half century, we are still ignorant of most of the fundamental processes of life both of plants and animals. We know that all growth comes from energy and that the only major continuing universal source of energy is the sun. We know that photosynthesis is the basic method by which the sun's energy is converted for the use of living things and that the materials used in this conversion come from the nitrogen and carbon dioxide of the air and the inert minerals of the soil. We have a superficial knowledge of all these things but our advances in production have to a large extent been empirical, and rule of thumb has too often been our only yardstick.

Biology, the most fundamental of all the sciences, has been the most neglected. It is in many respects the most difficult - and this may in part account for its lack of encouragement. Moreover, the physico-chemical sciences are concerned with principles and reactions which are independent of location, whereas conversion cycles - the energy flow among plants and animals in a given habitat-differ according to climate, latitude, nature of the soil as well as the composition of the communities.

There is an urgent need to explore the scientific background of growth and to make this knowledge available to all peoples on a world basis. What we have done in the north about production of food and clothing does not necessarily apply to many of the poorly nourished countries of the world with their different cultures and crowded populations. Scientific research is the only key to the production processes of the future. The problems of basic research however are so immense and so complicated, that they can only be tackled on a cooperative basis throughout the world.

This is the genesis of the International Biological Programme. It undoubtedly got its initial momentum from the success of the International Geophysical Year, which showed, inter alia, that scientific investigations could be coordinated internationally.

It was obvious in 1964, when the International Council of Scientific Unions commenced the planning phase, that organic production of food and its conservation was falling behind the needs of the world. Western medicine and technology were permitting more and still more human beings to exist while western law and order was reducing deaths due to local wars. The population was steadily increasing. During the period of "Expo" which is just finishing, it 
is estimated that the world increase will be about one and a half times the present entire population of Canada.

Natural selection as the guiding force of Evolution has been replaced by an anthropophilic type of selection. Man's attempt to place himself outside of natural laws has made such heavy inroads into the world's resources that Nature must ultimately reassert its influence.

Man, once he advanced from gathering plants and hunting animals for food, became a potential menace to all natural ecological communities and placing himself outside of his own natural habitat, created a new one by urban expansion, destruction of forest, erosion of soil and pollution of air and water. His progress was characterized by an excessively shortsighted technology which, tending to place man himself as the central purpose of society, is rapidly proceeding towards economic and social stagnation.

His pressure on our renewal resources for the use of a continually rising world population requires an enormously powerful effort on the part of Biology to ward off ultimate disaster.

This effort must be on a fully coordinated international level. It is urgent both in time and manpower because the time is late, the research is long and diverse and cannot be completed in even a few years' time. The approach must be dynamic not static, its objective conservation rather than preservation, although that too must be included.

The I.C.S.U. created a special committee for the I.B.P. which undertook the preliminary planning, and after careful study, it concluded that the basis of the programme should be limited to the fundamental approach of the flow of energy from the sun to plants and to animals, the utilization of nitrogen and other elements and, as a corollary, the adaptation of man to our changing environment.
The programme is called the "Biological Basis of Production and Human Welfare" and envisages a world wide study of organic production of land, fresh water and the seas, potentialities and uses of natural resources and human adaptability. It is limited to basic biological studies which could benefit from international collaboration and which are urgent because of the rapid changes now taking place in all environments.

This is initially a five year project but it is inevitable that it must last much longer. It only attacks part of the problem-the basic, underlying factors of production, of turning the energy of the sun and the inorganic elements of the atmosphere and the soil into food, clothing and fuel. It is not attempting to try to limit the population growth. It is not attempting the sociological task of reforming the human animal or trying to make him into a decent beast of prey. Nor do we attempt to stop the waste of the irreplaceable fossil fuels or minerals.

These are the tasks for other organizations. The aim of the Plan is the provision of data of a fundamental nature which can be used throughout the world in an attempt to postpone the ultimate dissolution of mankind. Our attention is devoted to an understanding of how we can increase our renewable resources-our plants, our animals-and how we can help to adapt human beings to the environments they are so rapidly and so radically altering.

The approach is fundamental and plans to obtain internationally comparable observations of the basic biological data and principles. It embraces much of existing biological research and the programme aims at coordination, rather than direction. Ecosystems should be classified so that they can be readily understood; classification must be precise, factual, free from preconceived ideas yet sufficiently flexible for progressive modification as new data become available. Handbooks on techniques and methodology are projected and ultimately 
new methods must be developed. Most important, new biological scientists must be trained.

In any given area there is a dynamic balance between organisms. In this, each individual species survives and reproduces, even though it is part of a local food chain. This differs according to latitude, climate, soil and composition of the communities and so the objective of the Programme is the development of human ecology in its broadest sense aiming at the production of a balance between natural resources and human fertility. The scope is wide and S.C.I.B.P. has envisioned seven main subdivisions of its basic theme and has appointed seven international sub-committees to enunciate and approve projects in each of these subdivisions.

\section{These are:}

P.T. Productivity of Terrestrial Communities
a) primary and b) secondary

P.P. Production Processes

a) solar energy and b) nitrogen fixation

C.T. Conservation of Terrestrial Communities

\section{P.F. Productivity of Fresh Water Communities}

P.M. Productivity of Marine Communities

\section{H.A. Human Adaptability}

U.M. Use and Management of Natural Resources

The next step was the formation of National Committees charged with the implementation of these programmes. These have been formed in nearly 50 countries, including our own, and they are truly national, comprising representatives from universities and government departments such as Agriculture, Fisheries, National Health and Welfare, Indian Affairs and Northern Development, National Museum, Transport, Energy, Mines and Resources, Atomic Energy, National Research Council and the Medical Research Council. Meanwhile seven local sub-committees have been organized by Canada on the same lines as the International Sub-committees. The C.C.I.B.P. has discussed programmes in all seven divisions and a number of these are in an advanced state of organization and some are already under way .

It should be emphasized that, while the I.B.P. is an International Programme, National Committees do their own planning within the general framework. Canada accordingly has proposed a limited number of studies in depth in various divisions. These will gradually be increased. The national sub-committees direct and elaborate and approve suitable I.B.P. projects and only projects approved by them, then by the C.C.I.B.P. and ultimately by the International Committes, constitute part of the programme.

Actually, of course, a number of existing research programmes fall within the purview of the I.B.P. and they have been incorporated into the programme. Projects are not financed directly by the C.C.I.B.P. but by the participating government departments concerned while the N.R.C. and M.R.C. finance University ones on a contract basis, requiring specific information requested by the C.C.I.B.P. on a programme previously approved by the central committee.

The central sub-committee on Production Terrestrial has classified the P.T. projects under five main "vertical" headings-grassland, woodland, shrub communities, wetlands and desert, plus supporting categories. They have also recognized three "horizontal" categories. They are primary productivity, secondary productivity and soil decomposition processes.

Our sub-committee feels that a few major, really comprehensive projects should be aimed at, estimating production at a given site and the establishment of the overall energy flow. As far as possible primary and secondary productivity should be studied at the same site and wild and manmodified environments compared in the same conditions. 
Primary Productivity aims at the measurements of net and total photosynthetic dry matter production, by the physical measurement and analysis of the plant biomass to determine its net periodic annual production. Secondary energy flow will be assessed through studies of insects, soil animals and micro organisms.

Productivity of Terrestrial Communities is at present being studied in depth at two sites:

The first is a Forest Project undertaken at the Petawawa Forest Experimental Station by the Department of Forestry and Rural Development and is a study of an aspen stand on land of Atomic Energy of Canada. The project director is Dr. P. J. Rennie and he is having assistance in special lines from university personnel from Waterloo, Guelph, McGill and Manitoba Universities. The Department of Transport is cooperating in micrometeorology measurements.

Related to this main project are studies of photosynthesis in aspen at Queen's University, at Guelph University and of nitrogen fixation at Macdonald College.

The second terrestrial project, a grassland one, is located on the old Matador range on the north bank of the South Saskatchewan River, on part of a provincial park acquired by the Government. It is a large piece of virgin prairie which has never been plowed, although it has been used for winter range. The area under study occupies some four square miles and the project leader is Professor R. T. Coupland of the University of Saskatchewan. He leads a team of some 12 other faculty members from both campuses who are specialists in various aspects - biomass, photosynthesis, microbiology, meteorology, as well as in insect, bird and small and large mammal populations. In addition microbiologists from the Universities of Manitoba and Calgary will be cooperating as well as scientists in the nearby experimental stations of the Department of Agriculture and the Department of Transport.
Various other terrestrial studies are under consideration while the Canadian Wildlife Service sponsors various secondary productivity projects at Petawawa, Matador and elsewhere.

Conservation Terrestrial has great, almost unlimited possibilities and is concerned with inland waters and peat land sites as well as more obvious implications. It is still under organization, although much has already been done in Canada by the Wildlife Service and the National Parks and it is under discussion with the Canadian Council of Resource Ministers.

The project on the Productivity of Fresh Water is also still under organization. Partly because of the lack of trained scientists, Canada's first step has been to initiate a training center in British Columbia at Marion Lake under Professor Efford of U.B.C.

It is obvious that much of our activity should be concentrated in northern Canada in the thousands of lakes in the Canadian Shield and the Far North. A considerable amount of work has already been carried out in this respect, not only by the F.R.B. but by university scientists in this and the adjacent provinces. But we must learn much more about the biotic potentialities of our huge reservoir of fresh water in the north-the greatest part of which cannot be removed to provide much needed water in the industrial regions in the south.

Maritime Productivity is a subject of great importance on all three of Canada's sea coasts, and the F.R.B. and its various stations have been very active in its study for many years now. The central sub-committee has emphasized human modifications of the marine environment and the urgent need for basic research in the effects of men's activities.

The Canadian Committee is sponsoring two inshore projects, in which the subject would be studied in depth. The first of these in the Straits of Georgia in British Columbia, is a project of the F.R.B. biological station at Namaimo which involves eight scientists including members of the 
Department of Oceanography at U.B.C. and the University of Washington.

The second, still in the exploratory stage, envisions a somewhat similar study in depth in various stations in the Gulf of St. Lawrence in which the F.R.B. is actively interested as also will be scientists from the universities in Quebec and Newfoundland.

Human Adaptability is of paramount importance in planning for the rapidly expanding world populations. Surprisingly little is known about human population biology and environmental physiology, although Canada for some years now has been active in investigations into cold tolerance and its biology. The I.B.P. is interested however in welding into an integrated and mutually helpful international programme, the various projects undertaken in the past and projected in the future. Standards of fitness have to be resolved and methodology put on a comparable footing; growth and development, resistance and susceptibility to disease, population genetics and so on are all on the programme. Nutritional studies including the use of new sources of food, are of particular interest. Progress is slow and must be so because several hundred contributions are being considered. Again it is necessary to put temporary limits on I.B.P. projects to ensure basic studies in depth.

Use and Management is an equally complex subject in some ways overlapping Human Adaptability, and the International Sub-committees have developed a number of special committees on some of the more important aspects such as Biological Control, Protein and other Biological Resources, Nutrition, Growth and Development of Cereals and Animal Gene Resources. Some of these are training programmes but one of most interest to Canada is the first because the Institute of Biological Control of the Department of Agriculture in Ontario, is already the outstanding example of international effort.
A joint committee of H.A. and U.M. is organizing human nutritional investigations and has laid down the major lines of investigation:

1) Assessment of nutritional status in relation to growth and physique, working capacity, thermal and altitude tolerance and genetic studies.

2) Intensive nutritional population studies based on habitat contrasts and

3) Nutritive value and acceptability of novel foodstuffs.

Agriculture, the basis of civilization, started in the Stone Age as a purely empirical method for saving work. It steadily became more established as well-developed techniques became available and about a century ago it became increasingly scientific. Fisheries are rather less well developed but in both there is still a great deal of basic knowledge required; the provision of this is the objective of the International Biological Programme. We are not aiming directly at solving the problems of tomorrow's food but at furnishing the scientific basis by which we can establish the productivity of our natural resources so that those responsible for the welfare of their own people can manage them with both efficiency and economy.

This basic information on biological productivity irrespective of political frontiers and as an international effort is the only hope of postponing what seems to be inevitable disaster.

Some time early next century, the world population will have reached five billion people and we will have strained our present resources almost to the breaking point.

The acquisition of this knowledge by the world seems the only hope for the teeming millions who are on their way and who will otherwise face famine and starvation.

Our system of ethics which developed with our western civilization, has left us with no option but to carry on the tasks started for us by the cave men and to render life more secure for future populations. 